\title{
Simulation of Dilute Acid hydrolysis of Wood Sawdust for Xylose Production using Aspen Plus
}

\author{
N.H.Ibrahim, W.H.W.Ibrahim, A.M.Mimi Sakinah, N.Harun and M.R. Othman
}

\begin{abstract}
Dilute acid hydrolysis is one of the most effective pretreatment methods for lignocellulosic biomass. The aim of this study is to develop and simulate process model for xylose production using Aspen Plus simulator. Based on experimental study for xylose production, a flowsheet has been proposed for a possible commercial production. Sawdust was used as a feedstock for the simulation as it has above $29 \%$ of xylan content. The hydrolysis of hemicellulose and cellulose to its monomeric constituents were modeled by a series of first-order reactions. A kinetic and stoichiometric based reactor was used for dilute acid hydrolysis and neutralization process. The results from the simulation were compared with experimental study from literature. Results from the developed process model show a good agreement with experimental study with $2.4 \%$ overall mean error for xylose and $4.5 \%$ overall mean error for glucose production.
\end{abstract}

Keywords - Acid Hydrolysis, Aspen Plus, Kinetic reaction Sawdust, Simulation.

\section{INTRODUCTION}

The production of fuel, gas and specialty chemical product from lignocellulosic feedstock has emerged as a worldwide market that is becoming increasingly important, drawing scientists and public attention. The biotechnology route for these productions has becoming more popular among researchers due to several factors including the global warming and also the increase of the crude oil price and legislative restrictions regarding the use of non-renewable energy source $[1,2]$. Many researchers agree that using lignocellulosic material as a renewable energy sources in these productions is a great potential solution for this global issue.

Licht FO (2006) was reported, less than $4 \%$ of the ethanol is produced synthetically from oil, while the rest is produced by fermentation from bio resources. The low cost and renewable nature of lignocellulosic material such as corn stover, sawdust tand sugarcane bagasse represents the ideal feedstock for their conversion into value-added products by biotechnological routes. The biotechnological route present several advantages on the chemical one, such as moderate conditions of

Nur Hatipah binti Ibrahim, Noorlisa binti Harun, Mohamad Rizza Othman, Faculty of Chemical \& Natural Resources Engineering, Universiti Malaysia Pahang, Malaysia

Wan Hanisah binti W.Ibrahim, School of Engineering, University of Warwick, United Kingdom

Mimi Sakinah Abdul Munaim, Faculty of Engineering Technology, Universiti Malaysia Pahang, Malaysia. temperature, $\mathrm{pH}$, pressure, high product selectivity and product biodegradation [3]. Therefore alternatives for the use of these materials to avoid the environment degradation were investigated. Meranti wood sawdust (MWS) is a lignocellulosic material that is abundantly wasted throughout the year in Malaysia. The high amount of xylan (29.22\%) content in MWS makes this biomass sufficient for xylose production [4]. The hemicellulosic fraction of MWS is easily hydrolyzed by dilute acid pretreatment process to produce xylose and glucose that can be used for the production of specialty chemicals and also as a potential substrate for microbial growth. The reduction of commercial xylose utilization could be obtain by using xylose as carbon and energy source for microorganisms.

In the world of software development, process simulation is becoming a requirement for all major process designs. Therefore necessity of simulation software vendor's work closely with the biobased producers to make sure that the software can help the production plants perform at peak operation condition. Established bioprocess simulators for these processes including Aspen Plus, HYSYS and SuperPro Designer that allow for the efficient and optimal process design, regulatory compliance and operational analysis of the process can benefit the production of biobased product. The proposed simulator; Aspen Plus will be selected as the best simulator tool for production of xylose in commercial scale. According to [5], Aspen Plus become the most widely used commercial process simulation software for steady state simulation since as a process simulator, Aspen Plus could offers many advantages.

Previous study by [1] using Aspen Plus discussed the economic potential (EP) for developed process model including upstream, downstream and fermentation section for butanol production by conversion of hardwood biomass shows that the EP of the process for the proposed flowsheet is about $1,254 \mathrm{k} € / \mathrm{yr}$ by determining the butanol production rate at 251 $\mathrm{kg} / \mathrm{h}$ and that the cost of the raw materials is assume to be negligible. Study by [6] using Aspen Plus to simulate different bio-transformation stages for different bio products; ethanol, xylitol, lactic acid and citric acid from pretreated lignocellulosic feedstock showed that the developed simulations allowed to evaluate mass and energy balances for each bioprocess which result in 133, 310, 162 and $157 \mathrm{~kg} / \mathrm{hr}$ of 
bioproduct outputs. The ethanol production process resulted in the lowest cooling and heating utilities required (2.6 and 3.0 $\mathrm{kW}$ ) as compared to other three products. The major advantage over many other software packages is it can easily handles solids. Besides the built in thermodynamic models and the unit operation models, there is no need to program them individually. Even with all the built in capacities, Aspen plus is easily customized when necessary $[7,8,9]$.

\section{MATERIALS AND METHODS}

Dilute acid hydrolysis (DAH) simulation was modeled as a steady state process. Aspen Plus software version 8.0 was employed to carried out the simulation process of the following stages: mixing, heating, dilute acid hydrolysis reactor, cooling, neutralisation reactor and solid separation. This process model was applied to the hydrolysis of wood sawdust. Two inlet streams were inserted; the solid biomass and liquid substrate (sulphuric acid and water).

NRTL (Non -Random Two Liquid) model is the most appropriate thermodynamic model for the components properties estimation owing to system characteristic which is operation pressures lower than 10 atm and system compounds are no-electrolyte polar substance [10]. According to the compositions of the wood sawdust it was essential to create hypothetical components for those that are not provided in the database of the simulator. The biomass input stream was assumed to be contained of pure elemental solids which are xylan, cellulose, and lignin and modeled as a combined solid feed stream and the mass fraction of each components are implemented according to [4]. Xylan, cellulose, lignin, calcium oxide and calcium sulphate was classes as conventional inert solids (CI solids) where these components are inert to phase equilibrium and salt precipitation/solubility and possible to react with conventional components [9]. The properties provided to the simulator for the conventional inert solids (cellulose, lignin, calcium oxide and calcium sulphate) were implemented according to [11] by input the molecular weight. Xylan component was defined by specified the heat of formation (DHSFRM), molecular weight and imported the molecular structure in component specification column. All these components were located in the CISOLID substream. For this study, component of extractive and ash is assumed to be inert thus the values were not added in simulation. The components specified in the biomass input stream was listed in TABLE I respectively.

For acid hydrolysis process, all the equations used in this study were inserted as kinetic reaction (based on rate constant and activation energy) and conversion reactions (based on stoichiometric) were inserted for neutralisation process and calculation was made in order to obtain the conversion for the optimum conditions of previous work by [4]. For the separation process, separator was chosen as a solid separation unit owing the properties for solid liquid separation.
TABLE I

SAWDUST COMPONENTS

\begin{tabular}{|c|c|}
\hline Component & Mass Fraction $(\% \mathrm{w} / \mathrm{w})$ \\
\hline Hemicellulose (xylan) & 0.31 \\
\hline Cellulose (gulcan) & 0.41 \\
\hline Lignin & 0.25 \\
\hline Extractives & 0.03 \\
\hline
\end{tabular}

In this work it was assumed that only the fast hydrolyzing fraction was included and xylan was breakdown to produce xylose. The reaction of xylan hydrolysis was considered by using first order reaction kinetics dependence on reactant concentration with an Arrhenius temperature associated for the first order rate constants $(\mathrm{ki})$ following “(1)”. Decomposition rate of cellulose to glucose was also considered by using first order reaction kinetics. Where $k i_{0}$ is the pre-exponential factor and $\mathrm{Ea}$ is the activation energy.

$$
k i=k_{i 0} e^{\frac{-E a}{R T}}
$$

From the above equation, the reaction constant $k i$ increases exponentially with temperature and pre-exponential factor $k i_{0}$ is the link between temperature and acid concentration variables in the reactions. Therefore, the kinetic model can be correlated with temperature and acid concentration through the empirical equation below;

$$
k_{\text {io }}=b_{i}[C a]^{\text {ai }}
$$

Where $b_{i}$ and $a_{i}$ is the regression parameter determined from experiment study and $\mathrm{Ca}$ is sulphuric acid concentration (\% $w / w)$. The $k i_{0}$ values of sawdust material for hydrolysate products can be calculated using generalized model developed by Rafique \& Sakinah (2012) as below;

$$
\begin{aligned}
& k_{10}=0.01778 \mathrm{Ca}^{1.2453} \\
& k_{20}=0.00276 \mathrm{Ca}^{0.44} \\
& k_{30}=0.00662 \mathrm{Ca}^{0.8135} \\
& k_{40}=0.00288 \mathrm{Ca}^{0.59} \\
& k_{50}=0.03003 \mathrm{Ca}^{0.5411}
\end{aligned}
$$

Two inlet stream; $3 \mathrm{~g} / \mathrm{min}$ of sawdust and $24 \mathrm{~g} / \mathrm{min}$ of dilute sulfuric acid $(6 \% \mathrm{w} / \mathrm{w})$ were mixed and the outlet stream temperature were heat up to $130^{\circ} \mathrm{C}$ in a heat exchanger (heater). The outlet solution are then feed to kinetic reactor for hydrolysis process. The optimal temperature and residence time in the hydrolysis reactor were claimed to be $130^{\circ} \mathrm{C}$ and 60 min respectively. Kinetic parameters used for the reaction process are based on experimental data and details are listed in the TABLE II. The hydrolysate solution of the reactor were cooled down to $25^{\circ} \mathrm{C}$ using heat exchanger (cooler) prior to filtration in order to facilitate gypsum formation and removal from hydrolysate solution. The hydrolysate solution are then feed to conversion reactor for neutralization process where calcium oxide flakes are added at $25^{\circ} \mathrm{C}$ and atmospheric pressure and the acid-base reactions took place to form salt 
and water. The input of conversion value were calculated based on initial content of xylan (29g xylan/100g MWS on o.d.b.) and cellulose (41g cellulose $/ 100 \mathrm{~g}$ MWS on o.d.b) in MWS. The remaining sulfate in the hydrolysate solution were then separated using solid separator (separator) prior to fermentation process. Temperature of hydrolysis reactor were then varies to $105^{\circ} \mathrm{C}, 115^{\circ} \mathrm{C}$ and $125^{\circ} \mathrm{C}$ to validate the developed simulation model result with experimental result.

TABLE II

KINETIC PARAMETER CONSIDER FOR THE REACTION IN PRETREATMENT REACTOR

\begin{tabular}{|c|c|c|}
\hline \multirow{2}{*}{ Reaction } & \multicolumn{2}{|c|}{$130^{\circ} \mathrm{C}$} \\
\hline & $\mathrm{K}_{1}\left(\min ^{-1}\right)$ & $\mathrm{Ea}(\mathrm{kJ} / \mathrm{mol})$ \\
\hline $\begin{array}{c}\text { Xylan } \rightarrow \text { Xylose } \\
\mathrm{C}_{5} \mathrm{H}_{8} \mathrm{O}_{4}+\mathrm{H}_{2} \mathrm{O} \rightarrow \mathrm{C}_{5} \mathrm{H}_{10} \mathrm{O}_{5}\end{array}$ & 0.16258 & 116.430 \\
\hline $\begin{array}{c}\text { Cellulose } \rightarrow \text { Glucose } \\
\mathrm{C}_{6} \mathrm{H}_{10} \mathrm{O}_{5}+\mathrm{H}_{2} \mathrm{O} \rightarrow \mathrm{C}_{6} \mathrm{H}_{12} \mathrm{O}_{6}\end{array}$ & 0.03006 & 30.862 \\
\hline $\begin{array}{l}\text { Xylan } \rightarrow \text { Furfural } \\
\mathrm{C}_{5} \mathrm{H}_{10} \mathrm{O}_{5} \rightarrow \mathrm{C}_{5} \mathrm{H}_{4} \mathrm{O}_{2}+3 \mathrm{H}_{2} \mathrm{O}\end{array}$ & 0.00842 & 11.351 \\
\hline $\begin{array}{c}\text { Xylan } \rightarrow \text { Acetic Acid } \\
\mathrm{C}_{5} \mathrm{H}_{8} \mathrm{O}_{4}+\mathrm{H}_{2} \mathrm{O} \rightarrow 2.5 \mathrm{C}_{2} \mathrm{H}_{4} \mathrm{O}_{2}\end{array}$ & 0.08012 & 13.049 \\
\hline
\end{tabular}

\section{RESUlt AND DiscuSSION}

Users are allowed to construct the flowsheet graphically by using the Process Flowsheet Window and the Model Library in Aspen Plus [8]. The model library in Aspen plus is equipped with an array of process equipment, modifiers and connectors from which a process plant and its sections can be designed.

Fig 1 shows the detailed process flow diagram of xylose production from wood sawdust. The hydrolysate solution produced from dilute acid hydrolysis process were contains fermentable sugars; xylose, glucose, furfural and acetic acid respectively. Products from the partial conversion of the lignin; phenolic compounds, ferulic acid and from xylan and cellulose; HMF, oligomer, arabinose were not included but they are assumed to have the same reactions and conversions as lignin, furfural and acetic acid. In the hydrolysis stage, xylan and cellulose are hydrolyzed to mono sugars (xylose and glucose). Severe hydrolysis condition (high temperature, strong acid concentration and longer residence time) may further hydrolyzed part of the produced xylose to furfural. Acetic acid is also released from the liberation of the acetyl groups associated with xylan.

Model validation for xylose and glucose production are plotted in fig 2 and fig 3 respectively. Results show a good agreement with previous experimental study. In this process $6.04,9.09,15.08$ and $14.95 \mathrm{~kg} / \mathrm{hr}$ of xylose were produced from the conversion of xylan. The highest xylose concentration produced is $15.08 \mathrm{~g} / \mathrm{L}$ at $125^{\circ} \mathrm{C}$. Xylose concentration is rapidly increased at temperature $115^{\circ} \mathrm{C}$ to $125^{\circ} \mathrm{C}$ and start to decrease at temperature $130^{\circ} \mathrm{C}$.

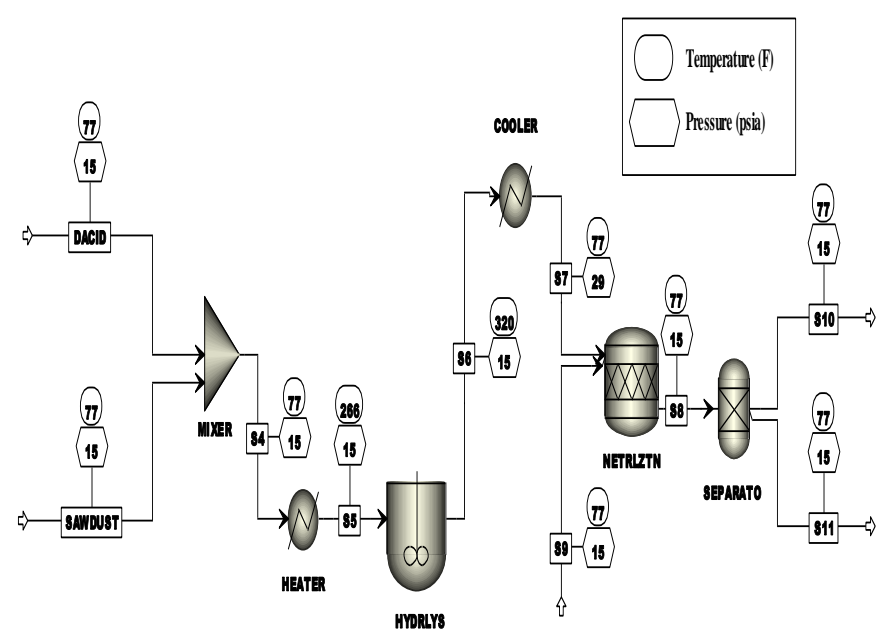

Fig 1: Flowsheet of model development process for the xylose production using Aspen Plus

The efficiency of the overall process model was calculated from the value of product produced in filtrate stream. Simulation result was validate with experimental result to evaluate the error of the process model. The highest error was at $105^{\circ} \mathrm{C}$ with $3.5 \%$ and the smallest error was at $130^{\circ} \mathrm{C}$ with $1.3 \%$. Overall the mean error is $2.4 \%$. Glucose formation also show a good trend with experimental study by [4]. In this process 1.11, 2.31, 2.54 and $4.06 \mathrm{~kg} / \mathrm{hr}$ of glucose were produced from the conversion of cellulose. The highest glucose concentration produced is $4.06 \mathrm{~g} / \mathrm{L}$ at $130^{\circ} \mathrm{C}$. Glucose concentration is rapidly increased at temperature $125^{\circ} \mathrm{C}$ to $130^{\circ} \mathrm{C}$ and expected to continuously increased with increased temperature. The highest error was at $105^{\circ} \mathrm{C}$ with $5.1 \%$ and the smallest error was at $130^{\circ} \mathrm{C}$ with $4.0 \%$. Overall the mean error for glucose production is $4.5 \%$. The energy consumed for heating was $141.5 \mathrm{~kJ} / \mathrm{hr}$ respectively. This results are on a same order of magnitude as those presented by [12], where $154.4 \mathrm{~kJ} / \mathrm{hr}$ were consumed to heat the banana waste (pulp) to $125^{\circ} \mathrm{C}$.

High concentration of xylose and glucose is prior to fermentation process for the various bio products; ethanol and xylitol. From the result it was evident that the developed process model were essential to produce high xylose concentration and low concentration of inhibitors were produced. Generally, higher temperature $\left(>130^{\circ} \mathrm{C}\right)$ is preferable for cellulose hydrolysis and longer hydrolysis process will result in decreasing xylose concentration due to degradation to inhibitor [13]. Under this condition, xylan was decomposed very fast to xylose and degraded completely to furfural. A considerable amount of xylose was released within $40-80 \mathrm{~min}$ and temperature between $120-130^{\circ} \mathrm{C}$ was critical to xylose recovery. Higher temperature could enhance the productivity of the xylose and glucose due to increase in collision of the sulphuric acid between feedstock. When temperature is raised to a certain level, part of hydrogen bond fracture among feedstock lead to the unstable structure thus increase the accessibility of acid molecules to the inner layers of the feedstock. 


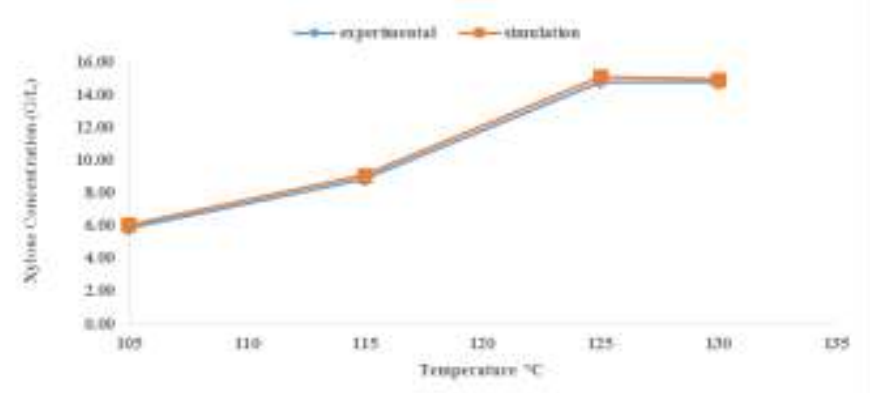

Fig 2: Production of xylose from experimental study by [4] and from simulation using Aspen Plus (this work)

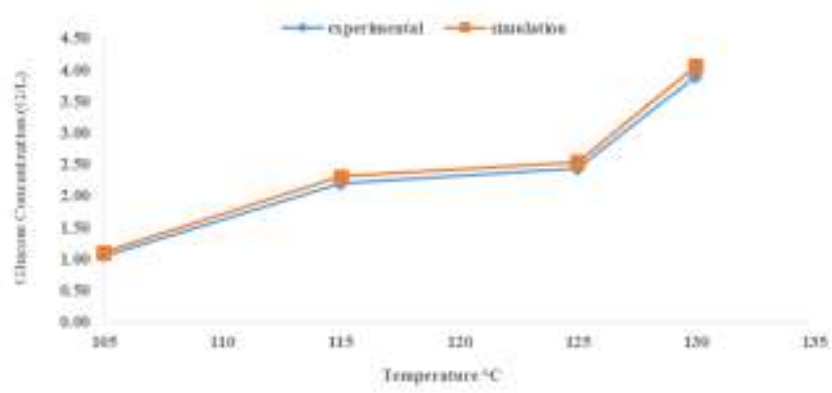

Fig 3: Production of Glucose from experimental study by [4] and from simulation using Aspen Plus (this work)

In general, furfural and acetic acid formation increased with operating temperature. In the hydrolysis of wood sawdust, furfural is generated as the main decomposition product with high pentose content. The concentration of furfural formed at $105^{\circ} \mathrm{C}, 115^{\circ} \mathrm{C}, 125^{\circ} \mathrm{C}$ and $130^{\circ} \mathrm{C}$ was $0.0037,0.0665,0.2372$ and $0.3865 \mathrm{~g} / \mathrm{L}$ respectively. Although the degradation of xylose to furfural was observed at all condition, the low amount of furfural formed can be negligible compared to the maximum amount of xylose produced $15.08 \mathrm{~g} / \mathrm{L}$ at $125^{\circ} \mathrm{C}$. Acetic acid is also produced in hydrolysis of wood sawdust. This product is generated for the hydrolysis of the acetyl groups present in the hemicellulosic heteropolymer [14]. The degradation reactions of acetic acid was slowly increased with increasing temperature. $5.04 \mathrm{~g} / \mathrm{L}$ of acetic acid was recovered at $105^{\circ} \mathrm{C}$ and the concentration was slightly increased to 5.16 , 5.24 and $5.44 \mathrm{~g} / \mathrm{L}$ at $115^{\circ} \mathrm{C}, 125^{\circ} \mathrm{C}$ and $130^{\circ} \mathrm{C}$. The low concentration of acetic acid showed that at low temperatures below $130{ }^{\circ} \mathrm{C}$, the only reaction conditions found to result in acetyl removal. The higher temperature and longer reactions times would be required to obtain significant acetic acid production.

\section{CONCLUSION}

Biomass from Meranti wood sawdust contains more than $29 \%$ xylan, which is a promising source for xylose production. Simulation of MWS hydrolysis was carried out with sulfuric acid under optimum experimental parameter to obtain a high concentration of xylose with low byproducts in the resulting hydrolysate. The maximum recovery of xylose is $15.08 \mathrm{~g} / \mathrm{L}$ which was achieved when the reaction was conducted at $125^{\circ} \mathrm{C}$ for $60 \mathrm{~min}$ with $6 \% \mathrm{H}_{2} \mathrm{SO}_{4}$ and LSR of $8 \mathrm{~g} / \mathrm{g}$. With $2.4 \%$ mean error it can be conclude that the simulation for xylose production is valid. For glucose production, the highest concentration produced is $4.06 \mathrm{~g} / \mathrm{L}$ at $130^{\circ} \mathrm{C}$. It was found that xylose production was highly affected by temperature, acid concentration and residence time which agreed with the experimental work by Rafiqul \& Mimi Sakinah (2012). Besides solving the disposal problems, the use of MWS to produce xylose also give back a high value product to the wood industry. The adequate result of the model validation by using Aspen Plus is a sequences method to examine the sensitivity of process parameter to process alternatives, equipment and operating cost reductions, and advances in conversion research.

\section{ACKNOWLEDGMENT}

The authors would like to express their gratitude for the financial support from Universiti Malaysia Pahang under Fundamental Research Grant Scheme (FRGS) RDU160123 and Graduate Research Scheme (Grant no. GRS 150385) for the financial assistance provided to complete this project.

\section{REFERENCES}

[1] Procentese, A., Guida, T., Raganati, F., Olivieri, G., Salatino, P., \& Marzocchella, A, "Process simulation of biobutanol production from lignocellulosic feedstocks," Chemical Engineering Transactions, 38: 343-348, 2014.

[2] Naik S.N., Goud V.V., Rout P.K., Dalai A.K., 2010, Production of first and second generation biofuels: a comprehensive review, Renew. Sust. Energy Rev., 14, 578-97 https://doi.org/10.1016/j.rser.2009.10.003

[3] Martínez, E.A. and J.A.F. Santos, 2012. Influence of the use of rice bran extract as a source of nutrients on xylitol production. Ciência $E$ Tecnologia de Alimentos, 32(2): 308-313. https://doi.org/10.1590/S0101-20612012005000036

[4] Rafiqul, I. S. M., \& Sakinah, A. M. M, " Design of process parameters for the production of xylose from wood sawdust," Chemical Engineering Research and Design, 90(9): 1307-1312, 2012. https://doi.org/10.1016/j.cherd.2011.12.009

[5] Luyben, W.L., 2004, Alternative Control Structures for Distillation Columns with Partial Condensers, Industrial \& Engineering Chemistry Research, 43 (20), 6416-6429 https://doi.org/10.1021/ie040146x

[6] García, A., Egüés, I., Sánchez, C., Barta, Z., \& Labidi, J, “ Study of Different Bio-Processing Pathways in a Lignocellulosic Biorefinery by Process Simulation,"Chemical Engineering Transactions, 35: 505-510, 2013.

[7] Wooley, R., Ruth, M., Sheehan, J., Majdeski, H., \& Galvez, A, "Lignocellulosic Biomass to Ethanol Process Design and Economics Utilizing Co-Current Dilute Acid Prehydrolysis and Enzymatic Hydrolysis Current and Futuristic Scenarios," NREL Report TP-58026157, 1999

[8] Aspen, Aspen Plus: Getting Started Building and Running a Process Model., 2003. Aspen Technology.

[9] Aspen, Aspen Plus: Introduction to Flowsheet Simulation., 2000. Aspen Technology.

[10] Peralta-Ruíz, Y., Pardo, Y., González-Delgado, Á., \& Kafarov, V, "Simulation of bioethanol production process from residual microalgae biomass," Computer Aided Chemical Engineering, 30: 1048-1052, 2012.

https://doi.org/10.1016/B978-0-444-59520-1.50068-3

[11] Souza, P. K. De, Sellin, N., Souza, O., \& Marangoni, C, “ Simulation of Dilute Acid Hydrolysis of Banana Waste for Ethanol Production: Comparison between the Use of Fruits , Peel and Pseudostem," Chemical Engineering Transactions, 32: 1141-1146, 2013.

[12] Chiaramonti, D., Prussi, M., Ferrero, S., Oriani, L., Ottonello, P., Torre, P., \& Cherchi, F, "Review of pretreatment processes for lignocellulosic ethanol production, and development of an innovative method," Biomass and Bioenergy, 46: 25-35, 2012. 
13th PARIS Int'I Conference on Chemical, Agriculture, Biological \& Environmental Sciences (PABEMS-18) Sept. 17-19, 2018 Paris (France)

https://doi.org/10.1016/j.biombioe.2012.04.020

[13] Kim, J. S., Choi, W. Il, Kang, M., Park, J. Y., \& Lee, J," Kinetic Study of Empty Fruit Bunch Using Hot Liquid Water and Dilute Acid," Appl Biochem Biotechnol, 167: 1527-1539, 2012.

https://doi.org/10.1007/s12010-011-9528-0 